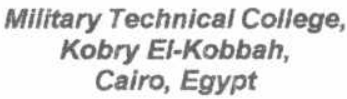

$9^{\text {th }}$ International Conference

On Aerospace Sciences \&

Aviation Technology

\title{
Real-time Implementation of Proposed Electro-mechanical Control System for Automation of Main Gearbox and Clutch Operations of Motor Vehicles
}

\author{
Bahgat S.F. * ; El-Haddad M.A. * and Hammad G. **
}

\begin{abstract}
Improvement of motor vehicle performance can be realized by using computer for automation of different vehicle systems, one of these systems is the driveline, which includes the gearbox and clutch. The complete real-time implementation of the proposed computerized electro-mechanical control system for automations of main gearbox and clutch operations is described in this paper. The adaptation of the control module to the conventional vehicle is realized through studying of the operations carried out by the driver and introducing an interfacing control system with the microcomputer.

The hardware system consists of three subsystems, mechanical, electrical, and electronic parts. These subsystems are; (mechanical) shift mechanism which consists of lever guide mechanism, actuating motors and limit switches, (electrical) relay control card which consists of relay group and electronic circuit group, and (electronic) gate control card or electronic control card which generates the control signals for relay card process. Finally standard $1 / O$ card is used to perform the interfacing between the microcomputer and the proposed electro-mechanical system. Through this paper, we conclude that the optimization of vehicle module operations at level of automation of driveline by using microcomputer and the improvement of motor vehicle performance can be achieved. This control system may be added to any conventional vehicle to automate its manual transmission and clutch operations due to its modular design. It also can be used to facilitate vehicle drive and remote control of its operation. The system main parts, principle of operation, design and realization are described in this work.
\end{abstract}

\section{Introduction:}

For motor vehicles equipped with manual transmission, the driver has been required to make several movements on different levers in order to make a ratio change.

\footnotetext{
* Associate Professor, Egyptian Armed Forces, Cairo, Egypt.

** Graduate Student, Egyptian Armed Forces, Cairo, Egypt.
} 
Driver error during shifting, due to inexperience or carelessness, can cause damage to the transmission, which increase maintenance cost. Also the driver can not choose the optimum gear ratio which increases fuel consumption. The optimum gear ratio may be selected and shifted automatically by automation of the complete driveline including transmission and clutch operations. The automation allows the system to be designed to fulfill specific user requirements and provides assurance that the vehicle will be operated as designed. Automation protects the driveline from driver error during shifting of gears. Also, driver fatigue is reduced and maneuverability is improved, potentially decreasing trip times.

For military vehicles the necessity of remote controlled vehicles is to aid for removing the person from the direct danger zone on a battlefield and considered as protection from hostile action, support of human activities, protection of the soldier from threatening environmental influences while performing hazardous activity. Replacement of manpower is carried out for the following reasons; inadequate human abilities, extensive threat or danger, lack of personnel for routine activities. So, it increases military effectiveness in the battlefield and reduces manpower requirements.

To achieve these goals in an efficient and economical manner, a system of control can be added to the conventional vehicle driveline to change its manual transmission into automatic one and choose the optimum gear ratio, which is corresponding to minimum fuel consumption according to the vehicle operating conditions.

There are different applications of microprocessor to control gearbox shift operation. These applications are incorporated either with manual or with automatic transmission where shifting up or down is executed automatically. Different types of control systems are given as follows: -

(1) Electro-hydraulic control system for automatic transmission provides optimum shifting, lock-up points, and modulates the hydraulic pressure electronically to achieve superior shift quality [10]. Control over the transmission can be integrated with engine control to deliver improved derivability and better fuel economy. This system has four goals, Improved derivability, Improved efficiency and enhanced acceleration performance and reliability.

(2) Electro-pneumatic control system, as example of use of pneumatic power for control system is an automatic transmission called the CEEMAT (Converter Enhanced, Electronically Managed, Automatic Transmission). The CEEMAT was specially designed to suit military applications. It is a unique combination of currently available mechanical transmission products and the power and sophistication of electronic control [12].

(3) Electro mechanical control system is currently under development and converts a manual transmission into a fully automated transmission. The main parts of the controller are the Electronic Control Unit ( ECU), Clutch Actuator, X-Y shift unit and driver command console

\section{2- Proposed Electro-Mechanical Control System:}

\section{1- Function of the Proposed Electro-Mechanical System:}

In order to select the most economical gear position among usable gear positions, a control module is proposed. Its function is to determine the suitable choice of a gear 
speed and automate the driveline including transmission and clutch operations, and make possible for remote drive. The function of the proposed system replaces the operations carried out by the driver as shown in Fig. (1). For transmission a microcontroller is proposed to take decisions, which are conducted to operate different actuators that drive the mechanical linkages, so the shifting is automated and simplified.

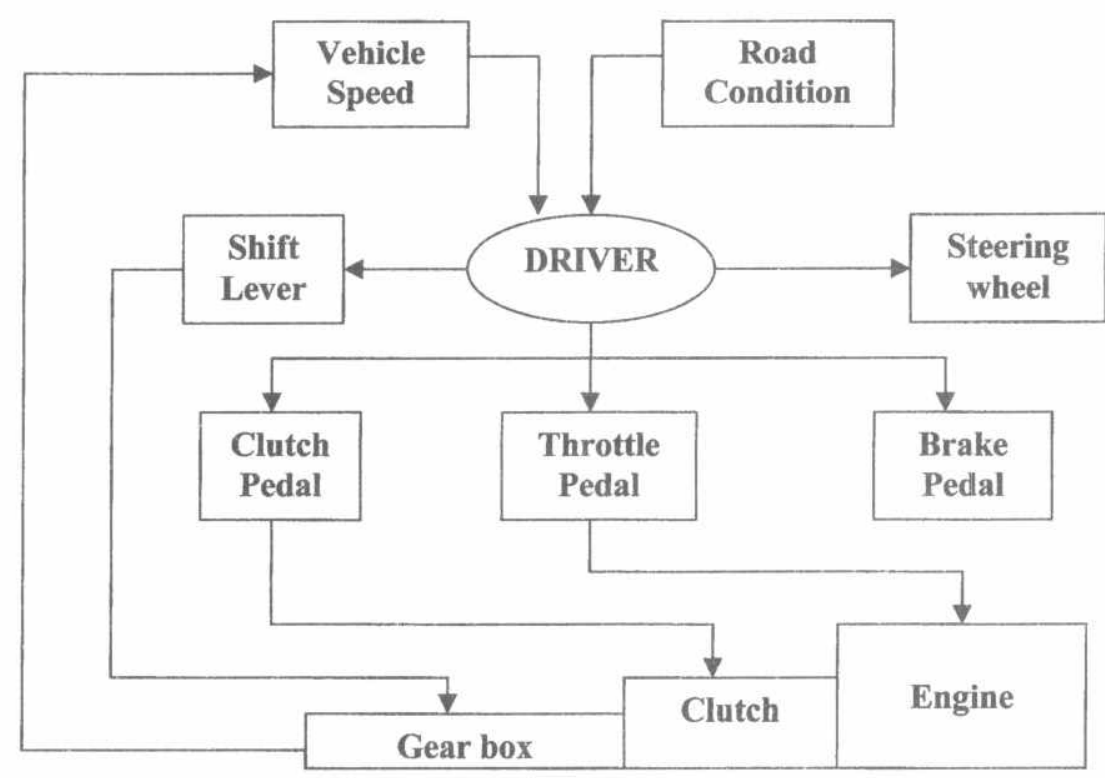

Fig. (1) Vehicle driver operations

A car chosen for implementation of the proposed system. Its transmission is straightforward three shafts, fully synchronized four-speed gearbox. The clutch is a conventional single dry plate type. Both clutch operations and gear changing are proposed to be done by Electro-mechanical actuators. The proposed control system consists of two major subsets, one is the HARDWARE, the electrical, mechanical and electronic components, the other is the SOFTWARE or computer program. The block diagram of the proposed control system is shown in Fig. (2). 


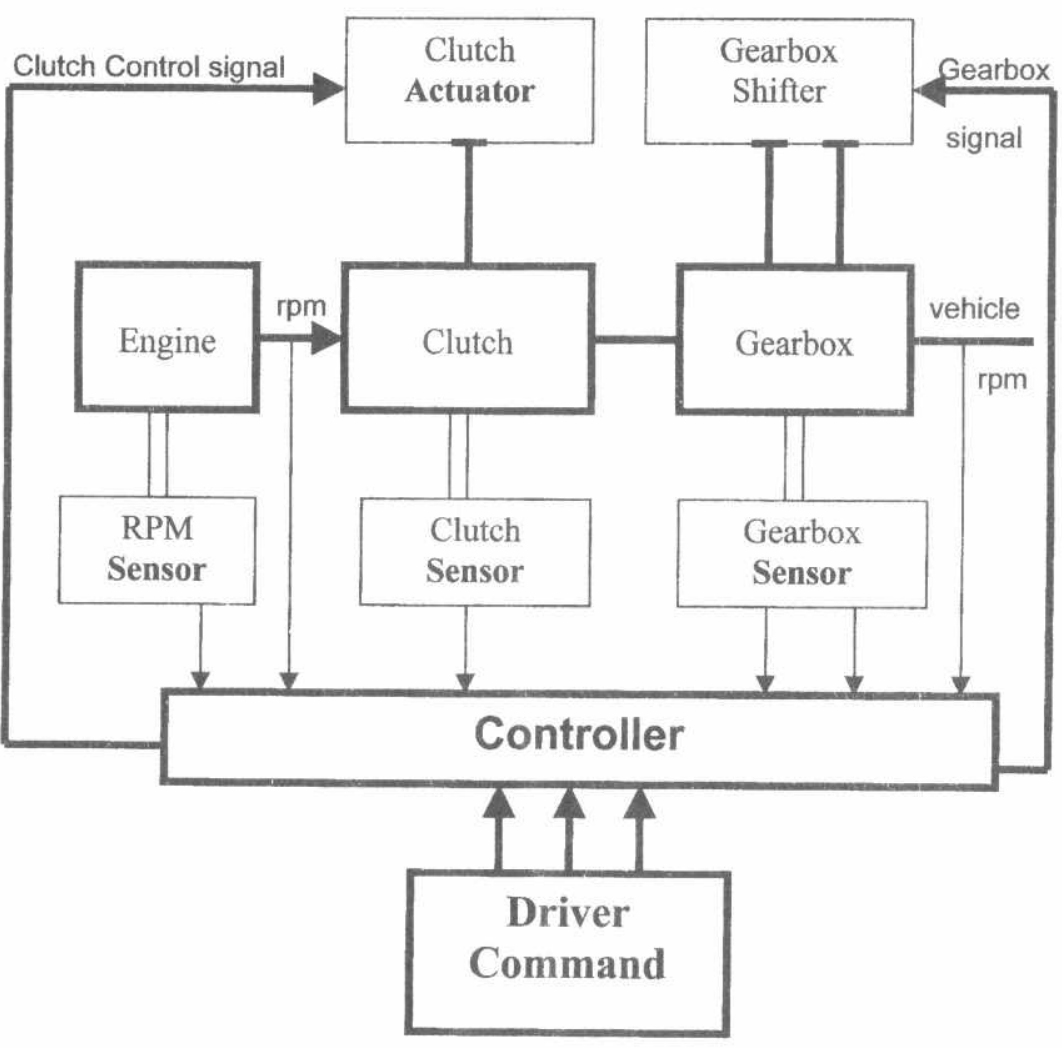

Fig.(2) Block diagram of the proposed control system

\section{2- Hardware of the Proposed Electro- Mechanical System:}

A- Electronic control unit (controller):

The proposed electronic control unit mainly consists of three parts: -

1-Microcomputer to process the data and determines the decision.

2- Relay control card is used to control the actuators operations.

3-Gate control card, which contains the main logic is used for interfacing

the decision from microcomputer to relay control card with perfect precision.

\section{B- Shifter mechanism:}

The main requirement for the proposed shifter mechanism are as follows:

1- Carry out the actuation's of main gear lever.

2- Reliable for most conventional gearbox lever.

3- Compatible with micro controller.

4- Simple design and accurate operations. 
The shifter mechanism consists of two actuator to carry out all required operations. The first actuator (A) set up the lever into three positions (shifting positions):

${ }^{*}$ Neutral position (middle position).

* High position (which corresponding the first and third gear position)

* Low position (which corresponding the second, fourth and reverse gear position) While the second actuator (B) set the lever into other three positions (I, II, III) choices positions according to shifting diagram. The driver operations to lever positions are 6 position, which are manipulated by the two-actuator $(A)$ and $(B)$. The proposed actuators $(A)$ and $(B)$ are a DC $12 \mathrm{~V}$ electric motor, which are controlled by the designed electronic circuit to the required positions. The combinations of the motions for the two actuator can carry out the required gear positions. The proposed Clutch actuator is also a DC $12 \mathrm{~V}$ electric motor. An electronic circuit necessary to control the actuator operations can do the clutch pedal automation.

\section{C-Sensors:}

The sensors are used to monitor the states of the control system variables, and they feedback the signals to the control unit. These sensors are:

\section{1- Vehicle speed sensor:}

Vehicle speed is monitored by a sensor fitted in the transmission train on the speedometer drive gear. A pulse generator, working on induction, hall effect, or photo-interruption principles, producing 2 to 8 pulses per revolution, up to a maximum speed of about $4000 \mathrm{rev} / \mathrm{min}$ may be used (is proposed). [6]

\section{2- Shifter mechanism sensors:}

To sense the gearbox lever positions, micro- switches (ON-OFF) are to be mounted on a metal sheet with special design corresponding to different positions of the lever, Sensors specifications are described also in reference [7].

\section{3- Clutch pedal position sensors:}

Clutch state can be sensed also by using two micro switches (ON-OFF) similar to shifter mechanism sensors, mounted on special pulley corresponding to clutch pedal positions (engage, disengage).

\section{D- Driver console:}

It Is used to input the control unit with required vehicle speed signal. The proposed sensor used in this case is control lever similar to the computer joystick. 


\section{3- Software of the Proposed Electro-Mechanical Control System:}

The control algorithm is stored in the microcomputer's memory. The main loop of the control program has three logical sections. These sections are inputs, choice and output subroutines. The input data of $1 / 0$ card has driver command and the shifter mechanism limit switch signals. The choice subroutine selects one of three subroutine, Neutral, Drive and Reverse. The output subroutine, which gives the signals, fed through the $1 / O$ card to gate control card, which activate and control the relay control card and actuators. The global block representation of the control algorithm is shown in Fig. (3). The electrical signals from the driving console or the system transducers are sent to the system control unit. The system program is divided into four modules: vehicle module, neutral module, drives module, and reverse module.

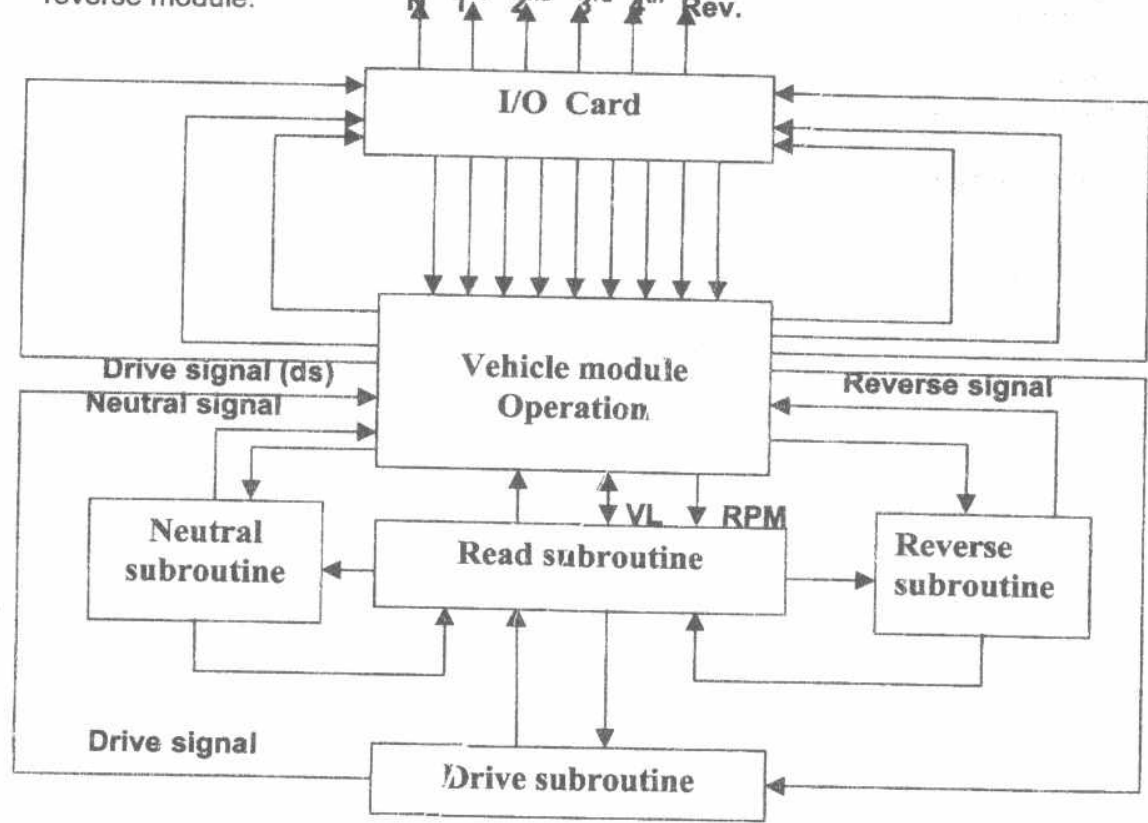

Fig.(3) Schomatic diagram of proposed control algorithm

VL

Vehicle speed

RPM

Engine speed

3-1 Vehicle mojule operation:

The algoritt. $\mathrm{m}$ of vehicle module operation is represented by the main flowchart shown in Fig.(4). The inputs to this module are engine RPM and driver command (dc) and the 'sutput is one of either starting, neutral, drive or reverse command. 
3-2 Read subroutine:

The function of this subroutine is to read different positions for gearbox and Clutch State. This module is required to determine the state before and after the decision of vehicle operation. The

algorithm of reading subroutine is represented by the flowchart shown in Fig.(5). The inputs /outputs for this subroutine are:

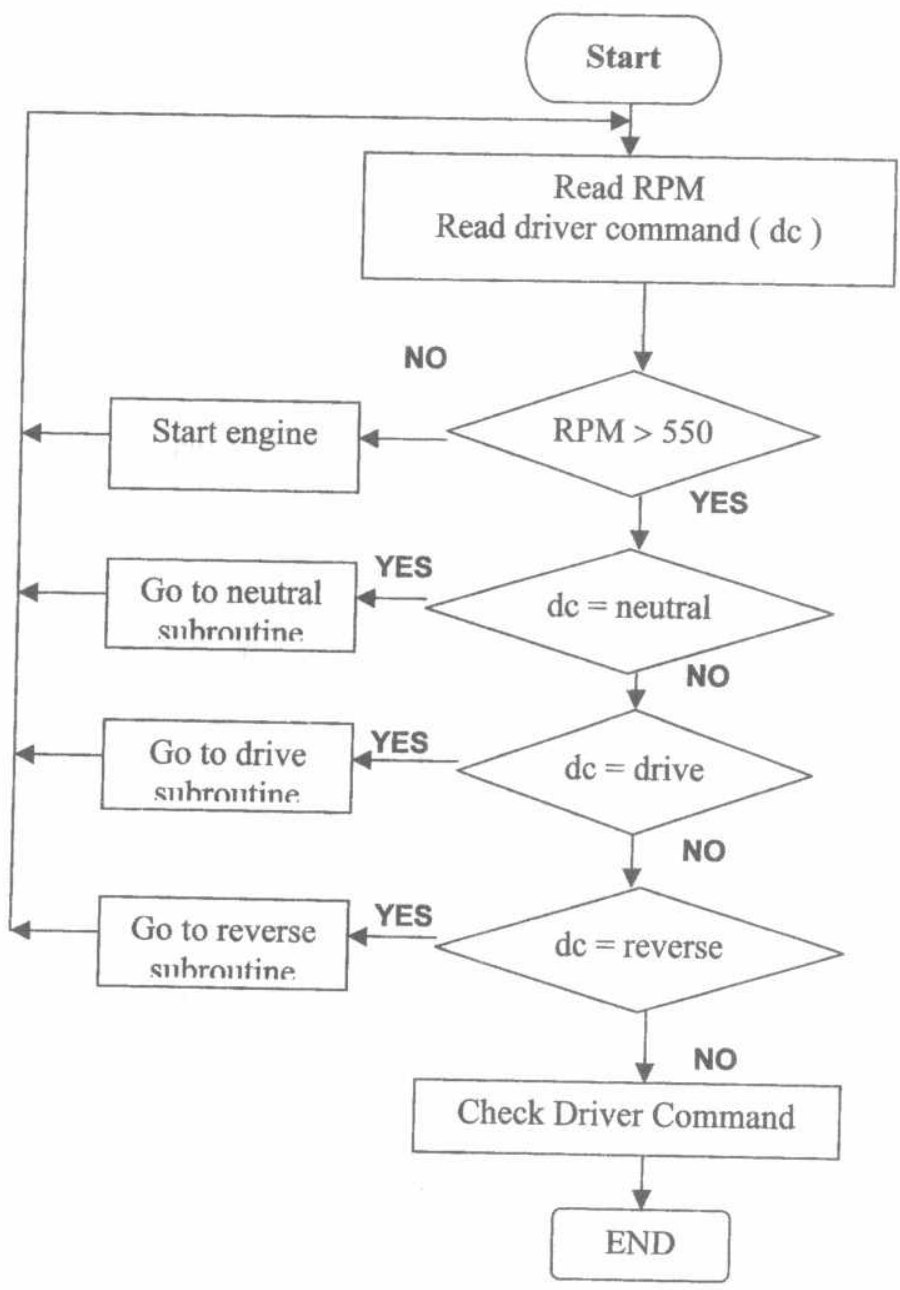

Fig.(4) Flowchart of vehicle module operation. 
*Inputs $\quad \mathrm{NI}, \mathrm{Cl} 1, \mathrm{Cl} 2, \mathrm{Cl} 3, \mathrm{HI}$ and $\mathrm{LI} \quad$ signals input to limit switches

* Outputs NO,CO1, $\mathrm{CO} 2, \mathrm{CO} 3, \mathrm{HO}$ and $\mathrm{LO}$ output signals from limit switches

The out put of this module is one decision of the following :

\begin{tabular}{|c|c|c|c|c|c|c|c|c|c|c|c|c|c|}
\hline $\begin{array}{c}\text { Output } \\
\text { GP }\end{array}$ & Meaning & $\mathrm{NI}$ & $\mathrm{NO}$ & $\mathrm{Cl} 1$ & $\mathrm{CO} 1$ & $\mathrm{HI}$ & $\mathrm{HO}$ & $\mathrm{LI}$ & $\mathrm{LO}$ & $\mathrm{Cl} 2$ & $\mathrm{CO} 2$ & $\mathrm{Cl} 3$ & $\mathrm{CO} 3$ \\
\hline 0 & neutral & 1 & 0 & - & - & - & - & - & - & - & $\ldots$ & - & - \\
\hline 1 & frist & - & - & 1 & 0 & 1 & 0 & -- & - & - & - & - & - \\
\hline 2 & second & - & - & 1 & 0 & - & - & 1 & 0 & - & - & - & - \\
\hline 3 & thrid & - & - & -- & - & 1 & 0 & - & - & 1 & 0 & - & - \\
\hline 4 & fourth & - & - & - & - & - & - & 1 & 0 & 1 & 0 & - & - \\
\hline 5 & reverse & - & - & -- & - & - & - & 1 & 0 & - & - & 1 & 0 \\
\hline
\end{tabular}

\section{3-3 Neutral subroutine:}

The neutral position for gearbox mean that no reduction ratio and output from gearbox is zero. The state of the gearbox lever position is controlled by the signal from microcomputer through the $1 / 0$ card, to gate control, to relay control card, which activates the necessary actuators to realize the required positions. The flowchart is shown in Fig.(6).

3-4 Drive subroutine:

The shifting of speed gear is controlled by the throttle pedal as a variable depending on driver console and other engine and road conditions. For the proposed system the output from optimization of engine operation is the input for drive subroutine operation. The inputs to drive operation is $V L$... i.e. vehicle speed [3].

\begin{tabular}{|c|c|}
\hline Gear Ratio & $\begin{array}{c}\text { Vehicle speed optimum rang (VL) } \\
{[\mathrm{km} / \mathrm{hr}][3]}\end{array}$ \\
\hline 1st gear & $0<\mathrm{VL} \leq 15$ \\
2nd gear & $15<\mathrm{VL} \leq 32$ \\
3rd gear & $32<\mathrm{VL} \leq 52$ \\
4th gear & $52<\mathrm{VL}$ \\
\hline
\end{tabular}




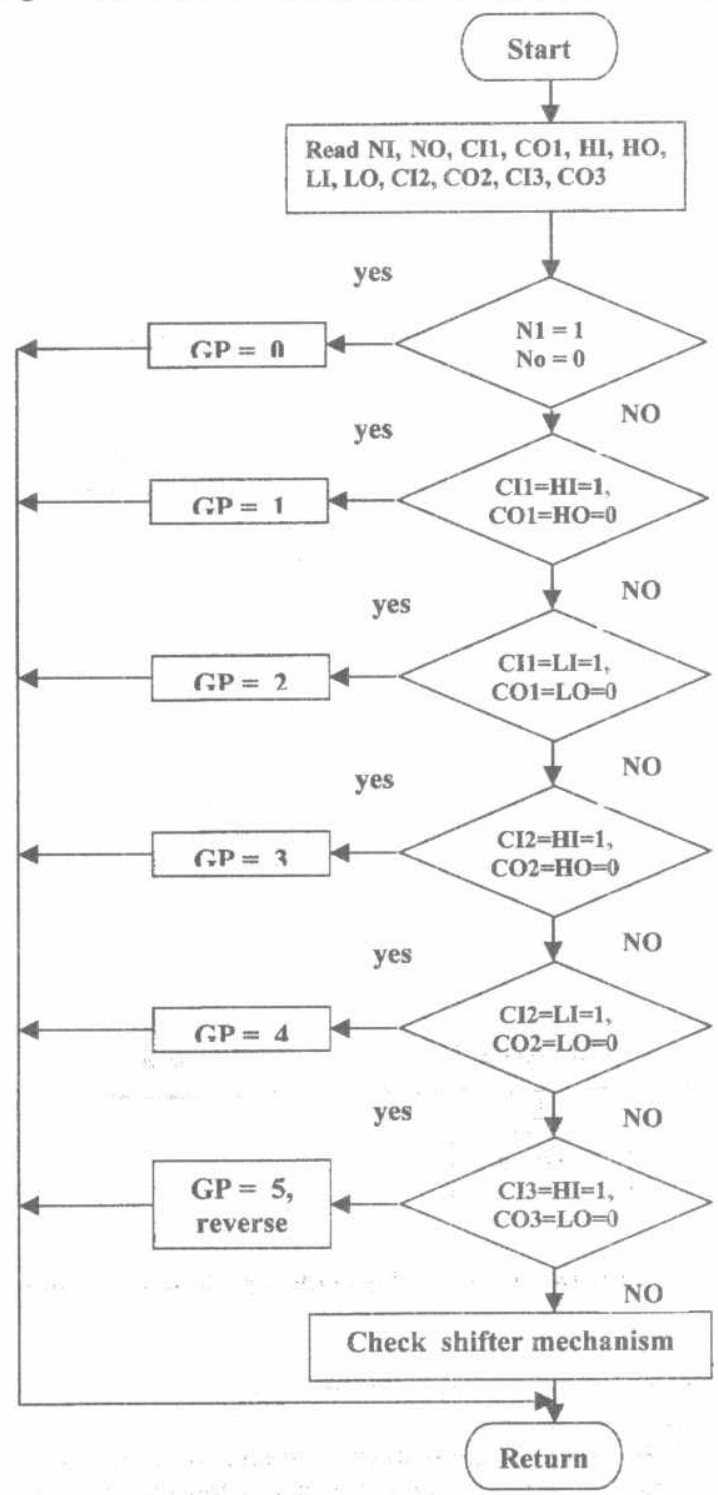

Fig.(5) Flowchart of read subroutine 


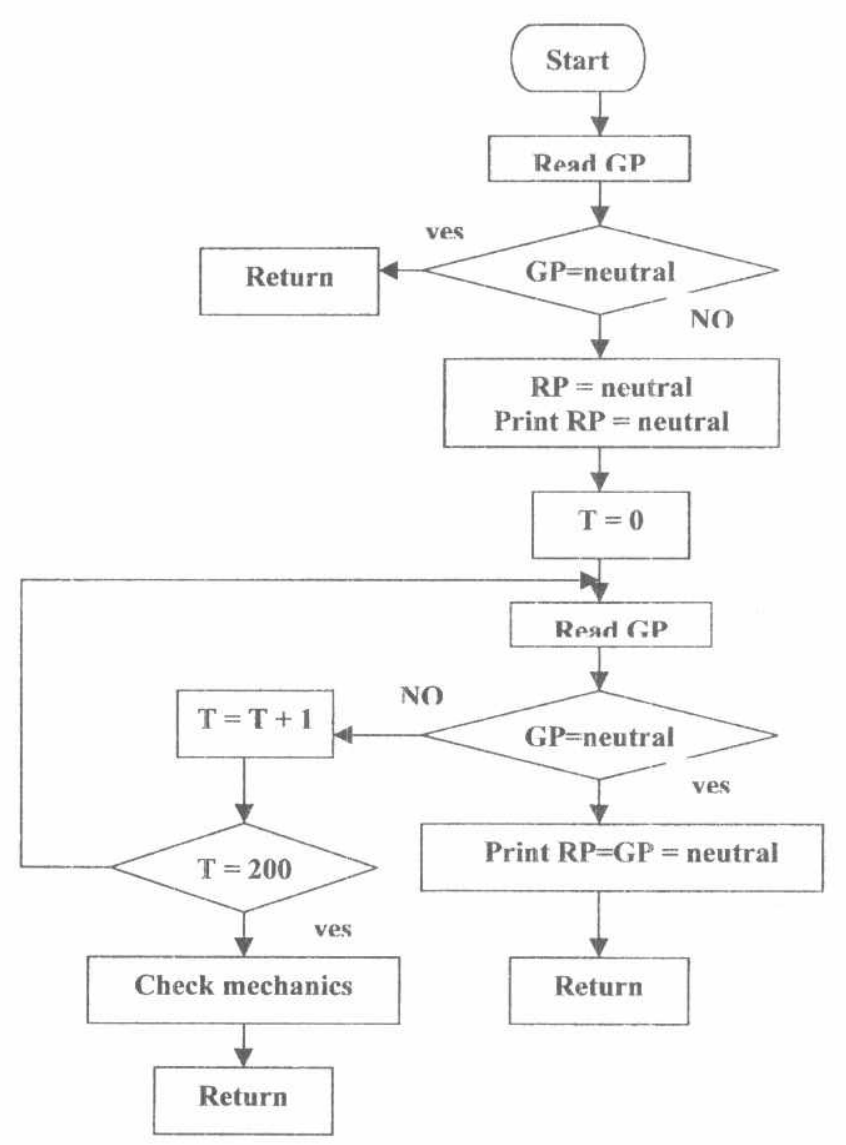

Fig.(6) Flowchart for neutral position subroutine

According to these inputs; the drive subroutine compares the vehicle speed, which comes from vehicle speed sensor and vehicle speed optimum range and determines the required speed. Flowchart of drive subroutine shown in Fig.(7).

The subroutine gives the order to feed the signal through the $1 / O$ card to control shifter mechanism operations and finally changes the gear box speed position to the required gear speed. The drive subroutine can determine the operation required from shifter mechanism when there exist any fault of shifter mechanism, it gives the order to signal to indicate the check needed to the mechanism. 


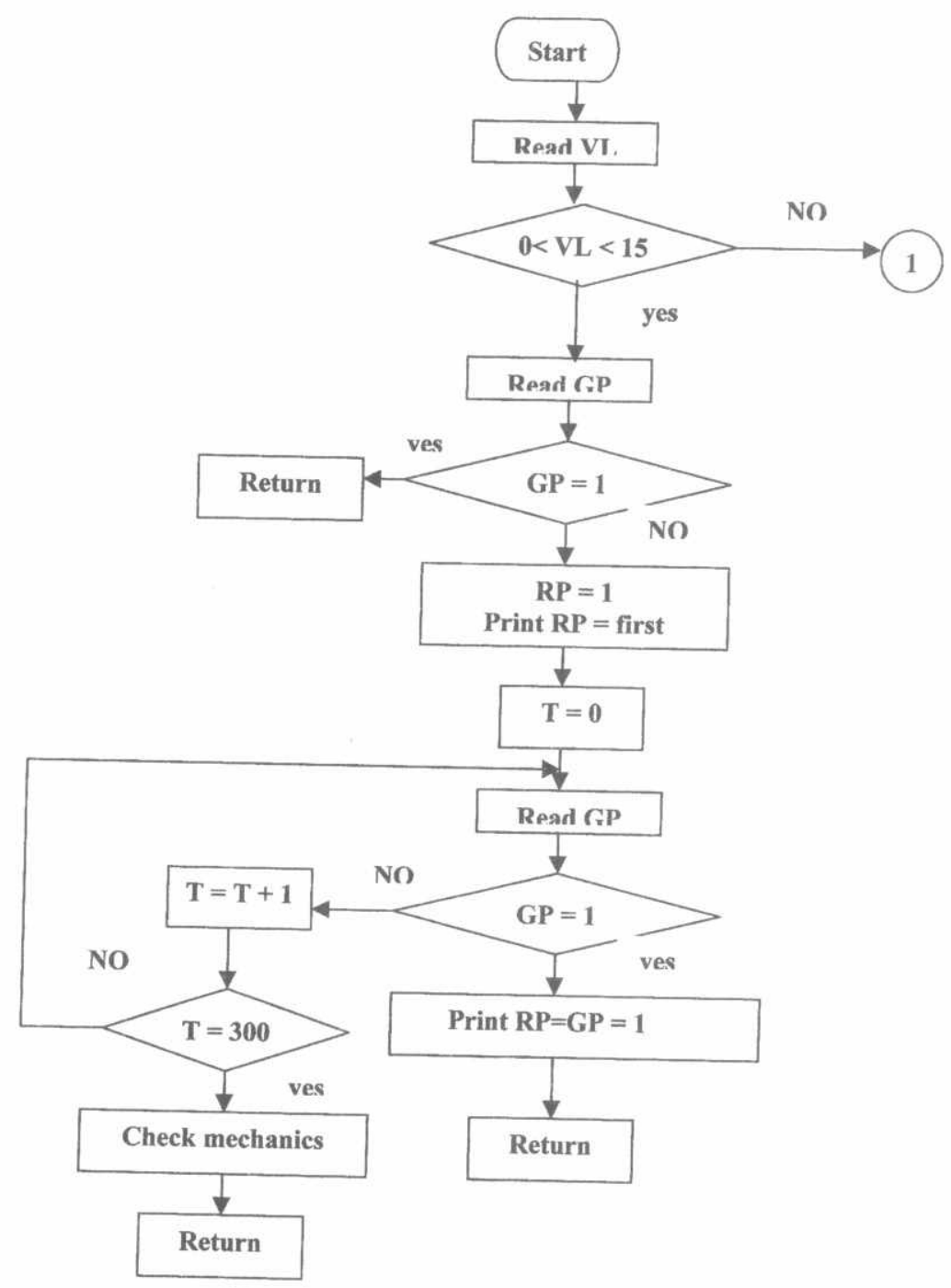

Fig.(7) Flowchart for drive position subroutine 


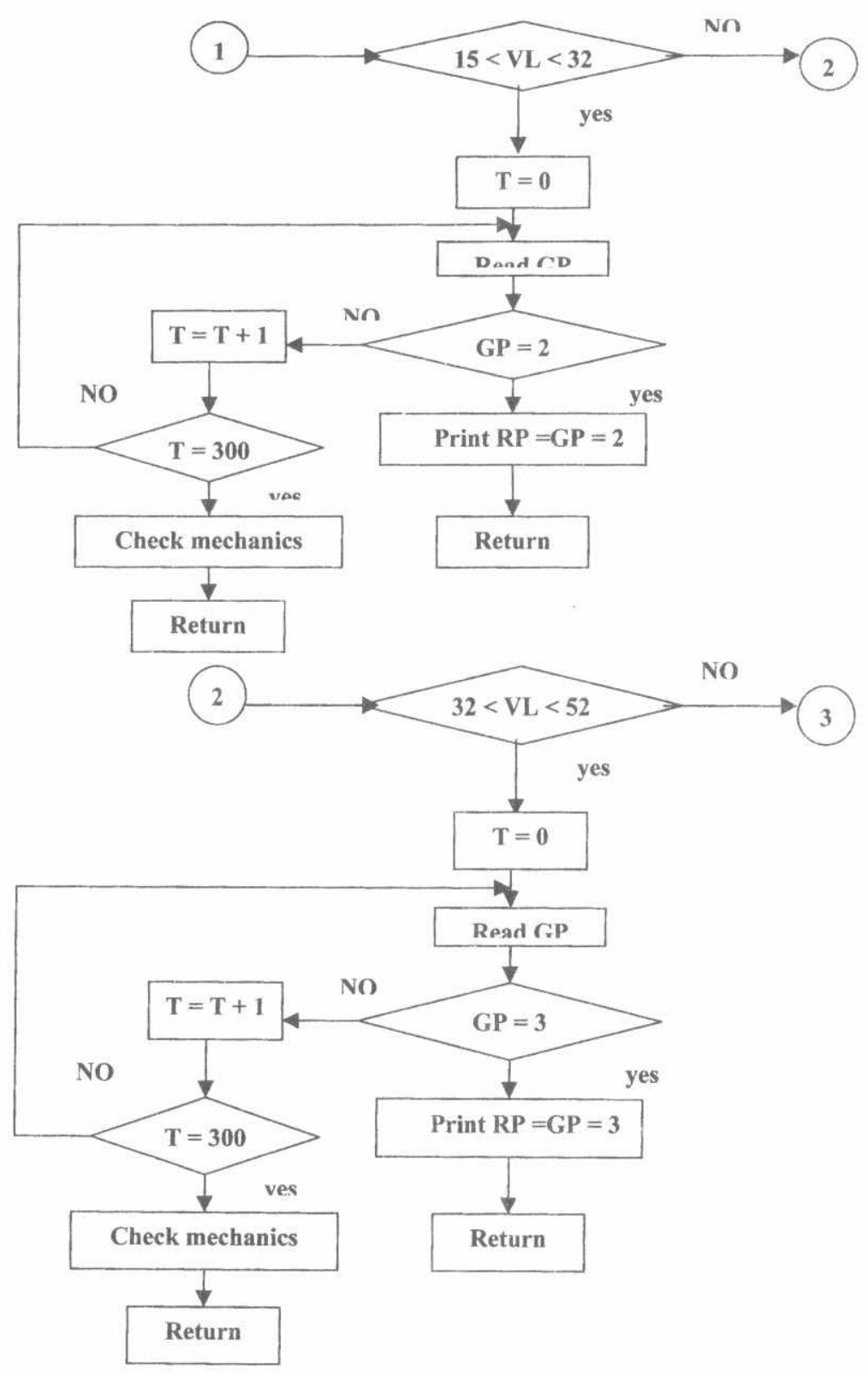

Fig.(7) Continue flowchart for drive position subroutine 


\section{1- Shifter Mechanism:}

The main parts of shifter mechanism are as follows:

(1) Lever guide mechanism. (2) Actuating motors. (3) Micro switches (sensors).

Fig.(9) show the plan view section for designed shifter mechanism.

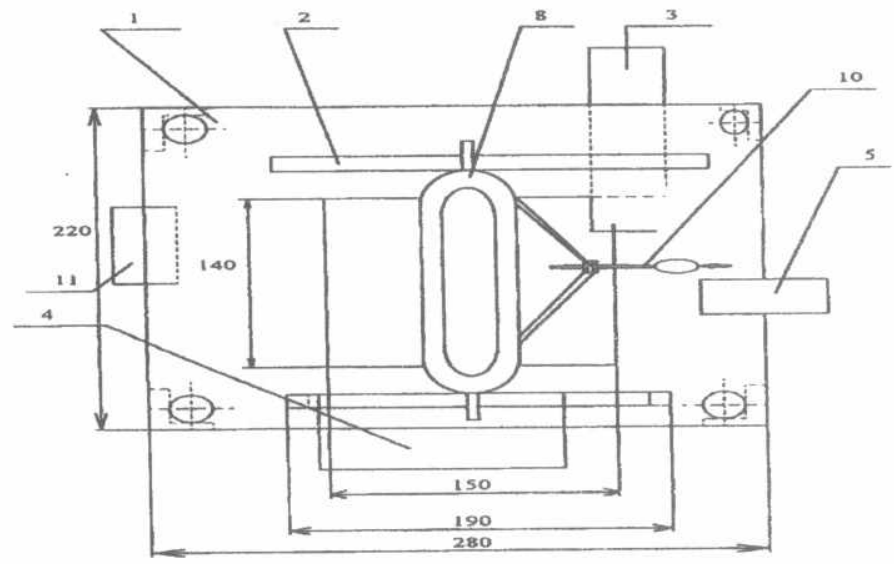
1- Shifting plates.
4- Shift actuator.
2- Guide piece.
3- Selection movable slot.
7- Selection actuator.
5- Gearbox lever.
6- Neutral position.
8- Clutch actuator.
9- Shift movable slot.

10- Guide piece.

Fig.(9) Plan view for designed shifter mechanism

(1) Lever guide mechanism which contain the following parts:

-Shifting plate:

It is a metal sheet flat plate that allows the gearbox lever to move forward and backward as well as right and left. The shifting plate dimensions permit to withstand other components. Assembly bolts on four stands fix the shifting plate. Fig.(10) shows diagram for lever guide mechanism.

\section{- Movable slot:}

It is a small plate having a long slot to guide the gearbox lever and move in reciprocating motion. Two pins one on each end of the slot guide the slot motion. The system contains two movable slots, one slot for the motion to right and left position realizing the choice positions I, II, III and the other for the motion forward and backward perpendicular in direction to the first one realizing the shift positions high, neutral and low. The intersection of the two movable slots gives the gearbox lever required position.

- Guide piece:

It is a long sheet metal having a narrow slot to guide the motion of movable slot by guiding the pin of movable slot. Each movable slot needs two guide pieces one to 
each side, then the system contains four guide pieces. The guide piece fixation is on the shifting plate.

\section{- Stand:}

It is a metal frame to support to stand the system in suitable position in the space around the gearbox lever, and adjusts the level suitable for operation of different component. The system has four vertical stands and two cross stands. The cross stands are for fixation of the mechanism, and the base for mounting the clutch and shift actuators. Fig.(10) shows the diagram of lever guide mechanism.

\section{(2) Actuating motors which contain the following:}

\section{- Shift actuator:}

It is a $12 \mathrm{~V}$ - DC electric motor mounted on the cross stand on special base. The output shaft of the motor drives a lever to convert the rotary motion into longitudinal motion required to movable slot, and realizes shift process. The shift actuator has two directions of motion clockwise and anti-clockwise. Electronic circuit to automate the shift operations controls this motion.

\section{- Selection actuator:}

It is a $12 \mathrm{~V}$ - DC electric motor mounted on shifting plate, its output shaft drives a pulley in a rotary motion which is converted into reciprocating motion using connecting rod which controls movable slot motion. The selection actuator realizes the choice position automation, which is controlled by electronic circuit operation.

\section{- Clutch actuator:}

It is a $12 \mathrm{~V}-\mathrm{DC}$ electric motor mounted on backward cross stand. The output shaft rotary motion is connected to clutch pedal through a pulley, steel wire, and another pulley at clutch pedal. The rotary motion wraps the wire on the pulley and then pull, so the clutch pedals and realizes the disengagement process. The engagement process is realized by the actuator operation to reverse direction. Electronic circuit controls these two motions of the actuator.

\section{(3) Micro switches (sensors):}

The sensors required for sensing the shifter mechanism operation can be divided to: - Shift sensors

The shift process has three positions, to sense these positions; one sensor (on- off) is mounted at the required position with suitable fixation. That means the required three sensors operates at high, neutral and low positions.

\section{- Choice position sensors}

Selection actuator realizes the selection of choice position I, II, III. The required sensors for choice positions are three mounted on pulley tightly with selection actuator at positions corresponding to choice positions I, II, III. 
- Clutch operation sensors

The operation of clutch needs two sensors to determine the engagement and disengagement processes. The system sensors are (on-off) sensors, its operation to determine the required position.

System sensors and their symbols are shown in the following table.

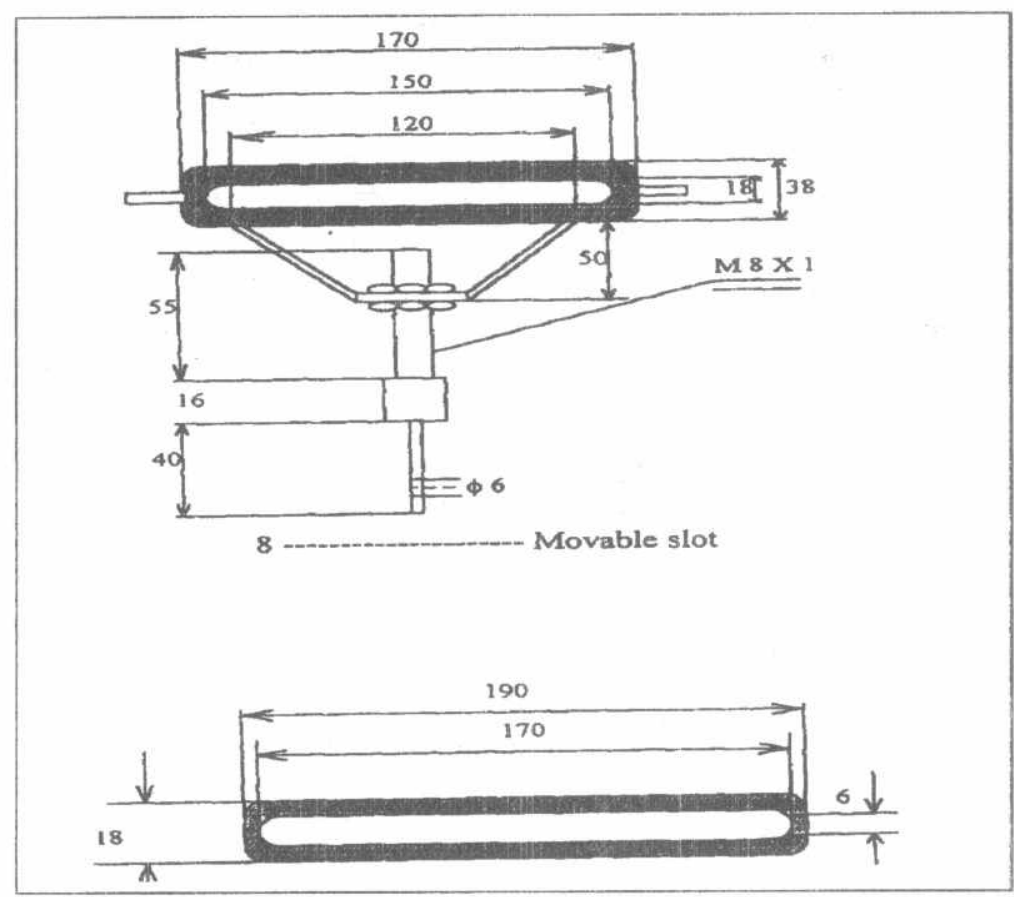

Fig.(10) Diagram of Lever guide mechanism.

\begin{tabular}{|l|l|c|}
\hline No & Sensor name & Sensor symbol \\
\hline 1 & High position limit switch & $\mathrm{H}$ \\
2 & Neutral position limit switch & $\mathrm{N}$ \\
3 & Low position limit switch & $\mathrm{L}$ \\
4 & Choice position 1 limit switch & $\mathrm{C} 1$ \\
5 & Choice position 2 limit switch & $\mathrm{C} 2$ \\
6 & Choice position 3 limit switch & $\mathrm{C} 3$ \\
7 & Engaging clutch limit switch & $\mathrm{E}$ \\
8 & disengaging clutch limit switch & $\mathrm{D}$ \\
\hline
\end{tabular}




\section{Shifter mechanism operation:}

The function of the shifter mechanism is to actuate the shifting lever according to the order of the control card, (output signals).

These output signals are used to execute different six lever positions.
1- Neutral position.
2- Reverse position.
3- $1^{s t}$ gear position.

4- $2^{\text {nd }}$ gear position.

5- $3^{\text {rd }}$ gear position

$6-4^{\text {th }}$ gear position.

These six lever positions required from shifter mechanism during its operations shown in Fig(11).

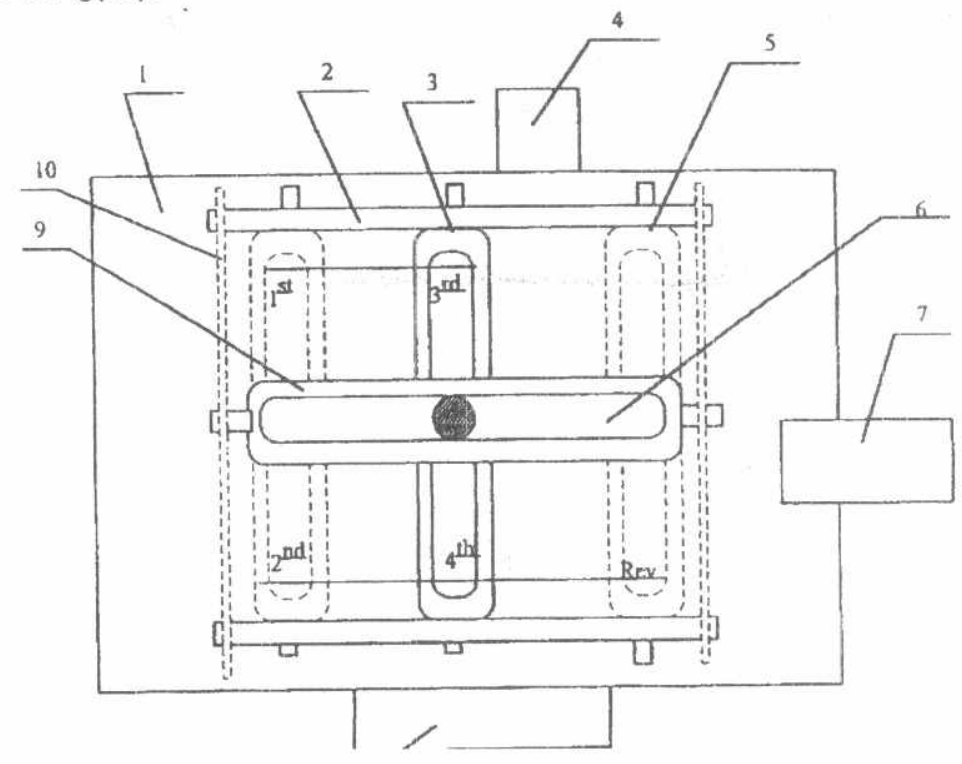

1- Shifting plates.

4- Shift actuator.

7- Selection actuator.

10- Guide piece.
2- Guide piece.

5- Gearbox lever.

8- Clutch actuator.
3- Selection movable slot. 6- Neutral position. 9- Shift movable slot.

Fig.(11) Schematic drawing for six gearbox position.

\section{4-2 Relay Control Card:}

\subsubsection{Relay control card description:}

The inputs to this card are electronic signals from gate control card and the outputs are electric power necessary to the operation of shifter mechanism actuators.

Relay card consists of two groups:

\section{A- Relay group:}

The electronic circuit according to the input signal that comes from the gate control card controls the relay operation. 
The relay card contains five $12 \mathrm{~V}-\mathrm{DC}$ relays distributed as follow:

- Two relays to automate clutch actuator operation

- Two relays to automate shift actuator operation

- One relay to automate selection actuator operation.

B- Electronic components group:

This group contains transistor, diodes and resistance; relay operation needs electronic circuit that consists of one transistor, one diode and two resistance. The assembly of the two groups on the board including all connections with inputs and outputs gives the layout of relay control card.

\subsubsection{Design and realization of the relay control card:}

The design and realization of the relay control card can be achieved by design of three electronic circuits for automation of :

a- Shift actuator operation.

b- Selection actuator operation.

c- Clutch actuator operation.

A-Design of electronic circuit for automation of the shift actuator operation Fig.(12) shows the circuit diagram for automation of the shift actuator operation. If the input signal from gate control card is in shift position high, then this signal control the coil of the relay to close its contacts permitting the current to pass and drive the shift actuator. This process is repeated for the other position.

B-Design of electronic circuit for automation of selection actuator operation: Fig.(13) shows the circuit diagram for automation of selection actuator operation. If the signal from gate control is required to select any position for choice position 1 or 2 or 3 , then this signal activates the relay to drive the selection actuator until the required position. This process is repeated with the other positions.

C- Design of electronic circuit for automation of clutch actuator operation: Fig.(14) shows the circuit diagram for automation of clutch actuator operation. The clutch actuator operation is required for all operations of gearbox shifting and neutral position, therefore the signal required to activate the relay of disengagement and relay of engagement is coming from gate control card. The engagement of clutch process after the complete required gearbox position.

\subsection{Gate Control Card :}

4.3.1 Gate control card description:

This card is the electronic control card of the realized proposed system It is considered as an interface card between microcomputer and the relay control card. Its input are signal from microcomputer and its outputs are signals to relay' control card.

4.3.2 Design and realization of gate control card:

Fig.(15) shows circuit diagram of gate control card. The signal from microcomputer is fed to the card and keeps its path by using three diodes forming three paths for each signal. These paths are as follows: 


\section{a- First path :}

The signal is fed to two Exclusive-OR gates, one activates disengagement and neutral circuits and the other, activates engagement electronic circuit according to designed time requirements.

\section{b- Second path:}

The signal is fed to the D-latch 4042 as the input data. The output from D-latch is fed to the AND gates to chose one choice position limit switch to activate the selection actuator circuit.

\section{c-Third path:}

The signal is fed to the D-latch 4042 as the input data. The output from D-latch is fed to the two ANC, gates for shift positions limit switch to activate the shift electronic circuit.

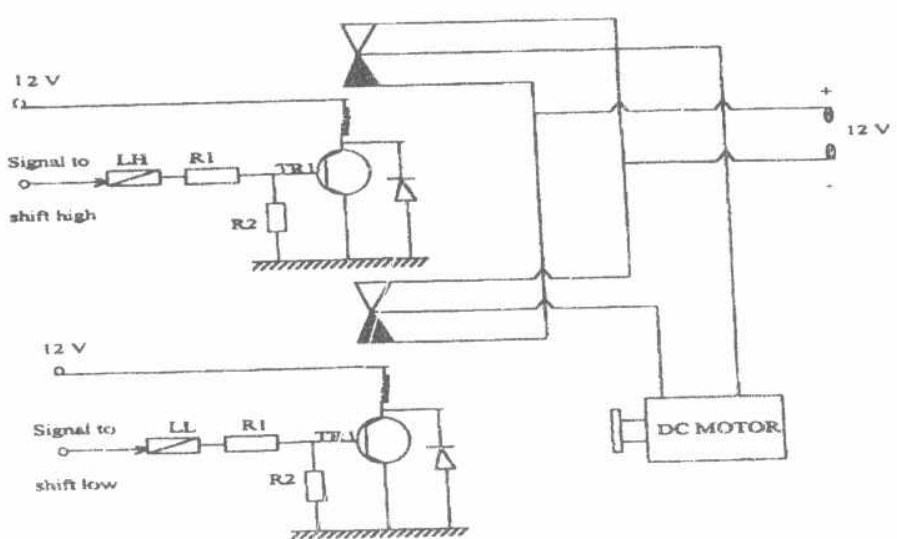

Fig.(12) Circuit diagrams for automation of the shift actuator operation

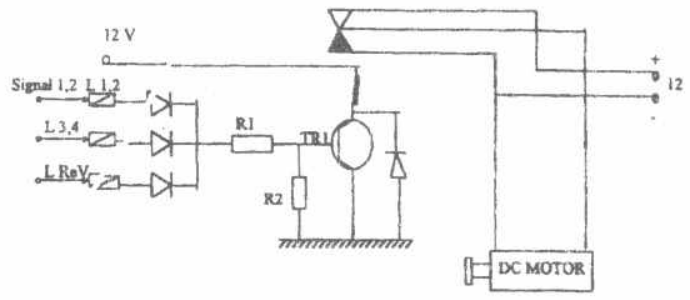

Fig.(13) C,ircuit diagrams for automation of selection actuator operation 


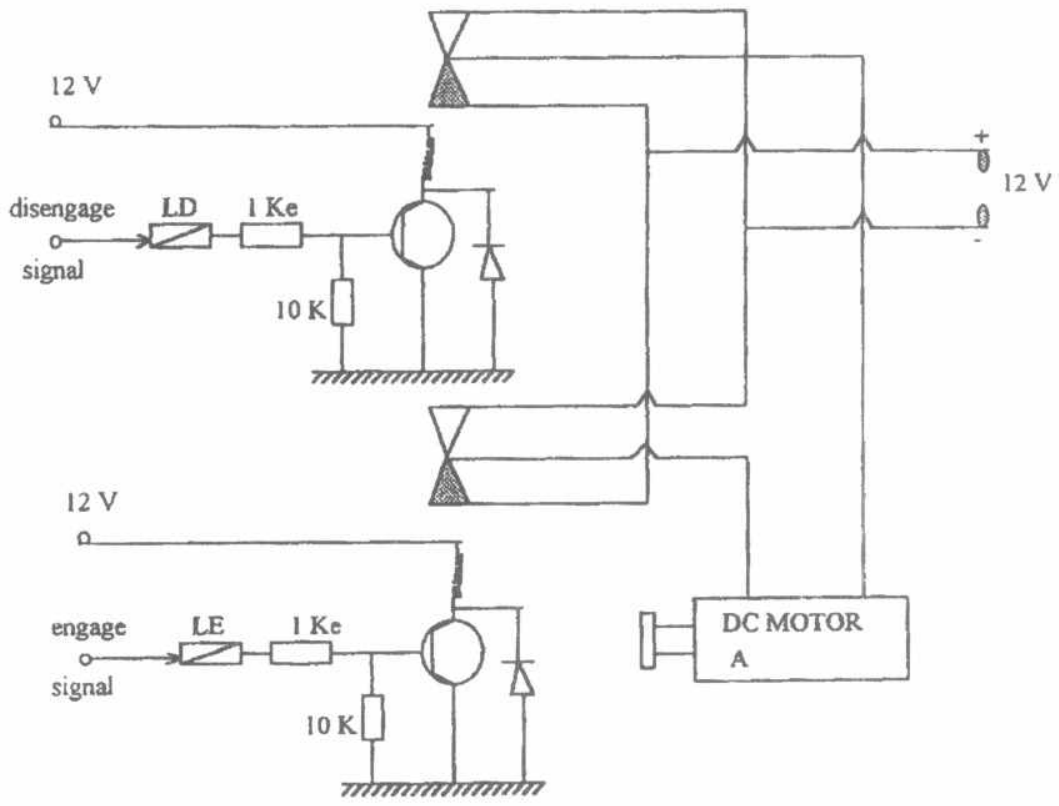

Fig.(14) Circuit diagrams for automation of clutch actuator operation.

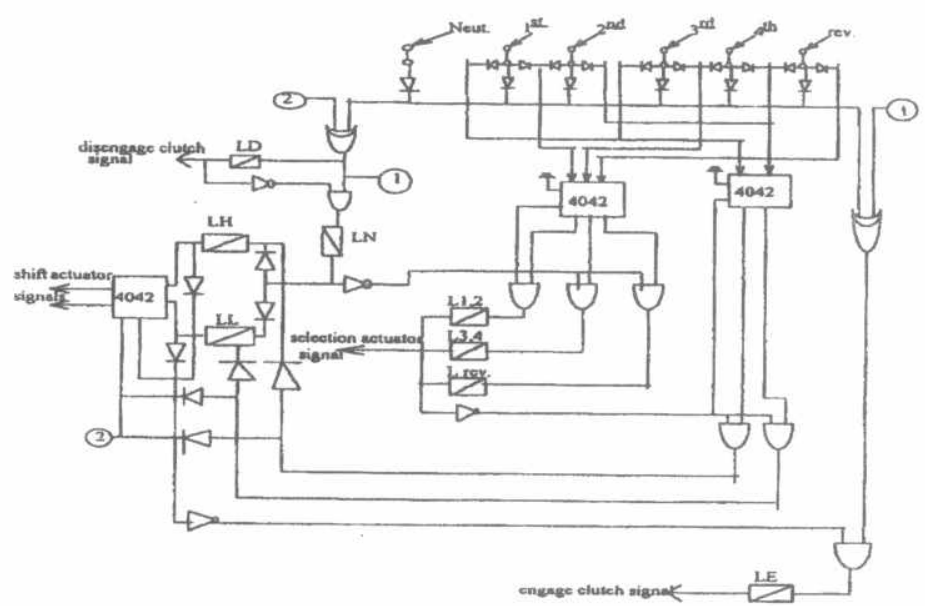

Fig.(15) Circuit diagram of gate control card. 


\section{5-Interfacing:}

$8255 \mathrm{~A} \mathrm{I/O} \mathrm{card} \mathrm{which} \mathrm{has} \mathrm{a} \mathrm{programmable} \mathrm{inputs} \mathrm{and} \mathrm{outputs} \mathrm{is} \mathrm{used} \mathrm{to} \mathrm{perform} \mathrm{the}$ interfacing between the microcomputer and the realized hardware of the electromechanical control system.

The design of the $1 / O$ card means determination the following : mode of operation, I/O address pin assignment and control word instruction to realize the interface of inputs and outputs. The number of outputs of the system are 6 and the number of inputs are 12 , then these inputs and outputs required 18 programmable $1 / O$ lines. The $8255 \mathrm{~A}$ I/O card has 48 programmable $\mathrm{I} / \mathrm{O}$ lines. The required logic state for data outputs are latched and data inputs ( reading logic ) are not latched, Then the design of $\mathrm{I} / \mathrm{O}$ operation can be as follows :

- Mode of operation is mode 0 (basic input/output).

Pin assignment port 1 which has 24 I/O lines, 3-port ( A, B, and C) I/O address select \& HIBO-\& HIBF as $1 / O$ port address.

- Control word instruction according to mode 0 port definition:

The 12 inputs are designed as follows: 8 inputs to port $\mathrm{A}$ and 4 inputs to port $\mathrm{C}$.

The 6 outputs are designed to port B.

The data output from microcomputer to port B I/o card are latched according to mode 0 of operation used.

\section{6-CONCLUSION:}

The improvement of motor vehicle performance can be achieved by using microcomputer, the optimization of vehicle module operation at the level of automation of driveline operation which depends on number of factors including: -

* Chosen gear ratio of the transmission

* Optimum vehicle engine operation

* Operating conditions of the vehicle

So, in order to automate the drive line operation, it is necessary to select the most economical gear position among usable gear positions to achieve compatibility of fuel economy with derivability taking into consideration of engine performance and road conditions.

For an automatic transmission, the driver merely selects a drive position, depresses the throttle pedal and goes. For conventional vehicles equipped with manual transmission and due to inexperience or carelessness of the driver during shifting of gears, the driver can not choose the optimum gear corresponding to the optimum vehicle engine operation. These causes increased in fuel consumption.

So, the optimum gear ratio can be engaged automatically by automation of the driveline, including the transmission and clutch providing override control of engine. This can be done by building up a control module, which can be added to any conventional vehicle transmission to change the manual transmission into automatic one, which engages the optimum gear ratio according to the vehicle operating conditions. A theoretical analysis and survey for the previous published work for similar control systems, hydraulic, mechanical or electronic types.

The proposed control system that consists of two major subsets, one is the HARDWARE, the other is the SOFTWARE or computer programs, the function of the proposed system performs the same operations carried out by the driver. This is identified and when manipulating clutch and gearbox lever. The realization of the proposed control system which is achieved by the design and production of its. It is 
clear that, the automation of main gear box and clutch operations can be controlled by the electronic control system its inputs are vehicle speed and output of optimization of engine operations which give the most economical gear position by comparison of engine fuel consumption data and vehicle speed and determine the optimum range for vehicle speed which the control system operation based on it.

\section{7-References}

[1] M. H. Westbrook, B. Sc. (Eng.), C. Eng., F. I. E. E., F. I. Mech. E., F. Inst. P "Automotive Electronics", Indexing terms : Review of progress, vehicles and transportation, control systems. IEEE PROCEEDINGS, Vol. 133, pt. A, NO. 4, JUNE 1986.

[2] Robin S. J., Siman D. L. Griffith, Keith W. and Anthony S., and Robert Cross, "Advanced Interactive Driveline Control", SAE paper No. 912680.

[3] I. Aref Ibrahim, "Optimization of Engine operation", M. Sc. In Mechanical Engineering, Chair of Auto., M.T.C. Cairo, 1992.

[4] R. H. Thring. "Engine Transmission Matching". SAE paper No. 810446.

[5] Richard C. Dorf, "Modern Control Systems", 1990 , F 13728.

[6] Al. Curll, "An Inside Look at Digital Automotive Electrical / Electronic Systems", Automotive Engineering, March 1990, pp. 36-42.

[7] Westbrook M.H., "Sensors for Automotive Electronics", Proc. 3rd Int. Con. on Automotive Electronics. I. Mech. E. 1981, PP. 33-38.

[8] William G. Wolber an Paul J.Ebaugh, "Automotive Engine Control Sensor's, 85 ", Electronic Systems Div., Cummins Engine Co., SAE paper No. 850491

[9] Osamu Ina., Yoshimi Yoshino, and Makio lida, "Recent Intelligent Sensor Technology in Japan", SAE, IC Energy, Dept., Nippondenso Co., Ltd. SAE paper No. 891709 .

[10] J. W. Austin, Cummins Engine Company, "Sensors and Actuator Requirements for Heavy Duty Diesels", SAE paper No. 830101.

[11] Yehia H. Hossam el-Deen. "Recent Applications of Microprocessor in the Field of Motor Vehicles" Tech. \& Armament Magazine, Scientific Research Section; January 1991.

[12] A. L. Miller, "Microcomputer Controlled Automatic Transmission", Borg-Wranger Research Center, Des plaines, 1L, Copyright 1983 Society of Automotive Engineering, Inc., SAE paper No. 820394.

[13] R. C. Holmes, R.R. Smyth and D. Speranza," The Automation of Mechanical Transmissions", Eaton Corporation, Eng. \& Research Center Southfield, MichiGan . 1988.

[14] Al. Curll, "An Inside Look at Digital Automotive Electrical / Electronic Systems", Automotive Engineering, March 1990, pp. 36-42.

[15] "Automotive Electronic Systems Handbook", 1988, printed and bound in Great Britain by Hardtnolls limited, Bodmin, Cornwall.

[16] S. Hirano, Alan L. Miller and Karl F. Schneider, "SCVT- A State of The Art Electronically Controlled Continuously Variable Transmission", Suzuki Motor Corp. Hamatsu, Japan, Borg-Warner Automotive, Inc. Ithaca, NY. SAE, paper No. 910410. 